\title{
Laparoscopic adrenalectomy for pheochromocytoma during pregnancy
}

\author{
Jerzy Lubikowski ${ }^{\circledR 1}$, Mariusz Chmielak ${ }^{\circledR 1}$, Dariusz Starzyński ${ }^{\circledR 2}$, Elżbieta Andrysiak-Mamos ${ }^{\circledR 2}$, \\ Cristina Croitoru ${ }^{\circledR 3}{ }^{3}$, Anhelli Syrenicz ${ }^{\circledR 2}$ \\ ${ }^{1}$ Department of General and Oncological Surgery, Pomeranian Medical University in Szczecin, Poland \\ ${ }^{2}$ Department of Endocrinology Metabolic Diseases and Internal Medicine, Pomeranian Medical University in Szczecin, Poland \\ ${ }^{3}$ Department of Vascular Surgery, Royal Victoria Hospital in Belfast, United Kingdom
}

Key words: laparoscopic adrenalectomy; pheochromocytoma; pregnancy

Pheochromocytoma (PCC) is a rare tumour of the adrenal gland, with typical symptoms like hypertension, palpitations, headaches, sweating, and anxiety. It is diagnosed in fewer than 7 pregnant women per 100,000 pregnancies [1]. Increasing blood supply to PCC, pressure from the growing uterus on the tumour, as well as foetal movement during pregnancy may stimulate catecholamine secretion and trigger a life-threatening hypertensive crisis. Untreated PCC significantly increases maternal and foetal mortality by up to $50 \%[2,3]$.

We present the case of a 32-year-old woman, 18 weeks pregnant, who presented with diarrhoea and recurring stomach aches. She was found to be hypertensive, with a blood pressure of up to 190/110 mm Hg. Ultrasound identified a $35 \times 22 \mathrm{~mm}$ adrenal tumour. Magnetic resonance imaging (MRI) confirmed the presence of a $37 \times 29 \times 31 \mathrm{~mm}$ pathological mass in the right adrenal gland (Fig. 1). Twenty-four-hour urine collection revealed markedly elevated metanephrines in repeated tests (291 and $492 \mathrm{ug} / 24 \mathrm{~h}$; reference range 0-350 ug/24 h). Based on the clinical picture, radiological images, and metanephrine levels, a PCC of the right adrenal gland was suspected and minimally invasive surgery was scheduled. The patient was admitted to the Department of Endocrinology, and her high blood pressure was successfully controlled with $\alpha$-blockers (doxazosin) 8 weeks prior to surgery. The patient underwent a laparoscopic lateral transperitoneal adrenalectomy, which took 225 minutes. The gravid uterus did not affect the surgical technique, and there were no adverse events during the procedure or the postoperative course. The patient was discharged uneventfully on day 5 postoperatively. Pathology and immunohistology confirmed the diagnosis of pheochromocytoma of the adrenal gland.

At follow-up the patient reported complete relief from symptoms and remained normotensive. Urinary metanephrine levels were normal on three consecutive measurements $(110,42,37 \mathrm{ug} / 24 \mathrm{~h})$. No pre- or post-operative complications to the foetus were detected. At 38 weeks of gestation, she gave birth, by caesarean section, to a healthy baby girl.

Currently there are no best practice guidelines for treatment of PCC in pregnancy, requiring clinicians to rely on their own experience and judgment. A multidisciplinary team approach should be tailored on

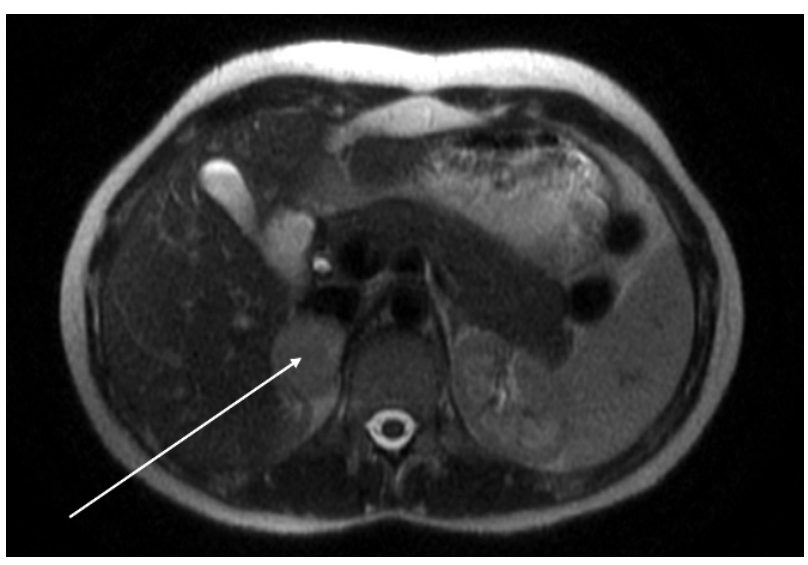

Figure 1. Magnetic resonance imaging (MRI) of the abdomen showing tumour of the right adrenal gland. Department of Imaging Diagnostics and Interventional Radiology, Pomeranian Medical University in Szczecin, Poland 
an individual basis to better manage the pathology $[4,5]$, plan the surgical technique, and oversee the necessary measures to enable optimal $\alpha$-blockade and $\beta$-blockade.

If PCC is diagnosed before the 24th week of pregnancy, we suggest that laparoscopic resection could be the treatment of choice, because the pregnant uterus at this stage does not restrict access to the tumour.

If PCC is diagnosed later and the maternal blood pressure is well-controlled, laparoscopic tumour re-section is recommended after delivery (preferably by caesarean section) or simultaneously with the parturition via laparotomy [2-4].

\section{Conflict of interest}

None declared.

\section{Funding}

None.

\section{References}

1. Lenders JWM, Langton K, Langenhuijsen JF, et al. Pheochromocytoma and Pregnancy. Endocrinol Metab Clin North Am. 2019; 48(3): 605-617, doi: 10.1016/j.ecl.2019.05.006, indexed in Pubmed: 31345526.

2. van der Weerd K, van Noord C, Loeve M, et al. Pheochromocytoma in pregnancy: case series and review of literature. Eur J Endocrinol. 2017; 177(2): R49-R58, doi: 10.1530/EJE-16-0920, indexed in Pubmed: 28381449.

3. Biggar MA, Lennard TWJ. Systematic review of phaeochromocytoma in pregnancy. Br J Surg. 2013; 100(2): 182-190, doi: 10.1002/bjs.8976, indexed in Pubmed: 23180595.

4. Donatini G, Kraimps JL, Caillard C, et al. Pheochromocytoma diagnosed during pregnancy: lessons learned from a series of ten patients. Surg Endosc. 2018; 32(9): 3890-3900, doi: 10.1007/s00464-018-6128-x, indexed in Pubmed: 29488089.

5. Chmielewski G, Walczyk A, Kowalska A. Two cases of pheochromocytoma in pregnancy: a multidisciplinary challenge. Endokrynol Pol. 2020; 71(1): 98-99, doi: 10.5603/EP.a2019.0039, indexed in Pubmed: 31566249. 